\title{
Research Trends of International Guides for Human Error Prevention in Nuclear Power Plants
}

\author{
Hyeon-Kyo Lim ${ }^{1}$, Hyunjung Kim ${ }^{1}$, Tong-Il Jang ${ }^{2}$, Yong Hee Lee ${ }^{2}$ \\ ${ }^{1}$ Department of Safety Engineering, Chungbuk National University, Cheongju, Chungbuk, 361-763 \\ ${ }^{2}$ I\&C and Human Factors Research Division, Korea Atomic Energy Research Institute (KAERI), Daejeon, 305-353
}

\begin{abstract}
Objective: The aim of this study was to comprehend major concepts and flows that penetrate international guides or standards for developing a quantitative possibility measure of human errors that can be committed or omitted in nuclear power plants. Background: For a few past decades, lots of researchers have studied the effect of stress and/or fatigue which can result in human errors. Thus, this study was carried out on the assumption that much of them were summarized as an international guidelines or manuals, if any, for human error prevention. Method: A literal survey was conducted with materials and documentation published by international organizations related with safety and standardization, such as ISO, OSHA, $\mathrm{NIOSH}, \mathrm{NASA}$, and so on with special reference to human error prevention through management of work stress and fatigue as major Performance Shaping Factors. Results: International guides or management manuals on stress or fatigue management for human error prevention hardly were found, and most researches seemed to concentrate on one of them individually. Conclusion: There was few vestige of research that studied both concurrently. However, it was verified that not a few researches have been tried to develop quantitative measures to estimate probability or job characteristics for human error prevention and/or performance downgrading. Application: The results of this study would help to develop a causal model of human errors due to work stress and fatigue that can result in unexpected accidents in nuclear power plant.
\end{abstract}

Keywords: Human errors, Accident prevention, Work performance, Stress, Fatigue, Human error possibility index

\section{Introduction}

인적오류가 복잡하고 기술적인 시스템의 기능 이상이나 사고와 깊은 관련이 있다는 것은 이미 알려진 지 오래이 다(Meister, 1971). 또한, 그 비율이 화학플랜트의 경우 $37.2 \%$ (미국) 내지 $51 \%$ (일본), 발전소의 경우에도 $20 \%$ (화력발전소) 내지 $46 \%$ (원자력 발전소)나 된다는 것도 새 삼스러운 보고는 아니다(Stewart, 1997). 원자력 관련 시설 의 경우 원자력 기술의 성숙기에 접어들면서 발전로는 물론 연구로 등에서 일어나는 고장정지 사건의 횟수는 매우 희귀
해지고 있지만, 그래도 해당 사건의 상당 부분은 인적요소와 관련되며(Arkin et al., 1989; Bell et al., 1989; Bento, 1990; Dennig et al., 1987; Lam et al., 1988; O'Reilly et al., 1988; Skof, 1990; Wu et al., 1989; Zech, 1988), 하 드웨어 기술의 발전에 따라 앞으로 그 비중이 더 커질 것으 로 예상되고 있다.

안전관리와 관련된 분야에서는 사고를 "물체, 물질, 사람 혹은 복사의 작용/반작용이 신체 상해를 일으키거나 그럴 가 능성이 있는 계획되지 않고 통제되지 않는 사상"이라고 정 의하는 한편, 사건(incident)이란 "업무활동의 효율을 저하 시키는 바람직하지 않은 사상(Heinrich, 1931)"이라고 정의

Corresponding Author: Hyeon-Kyo Lim. Department of Safety Engineering, Chungbuk National University, Cheongju, Chungbuk, 361-763. Phone: +82-43-261-2462, E-mail: hklim@chungbuk.ac.kr Copyright@2013 by Ergonomics Society of Korea(pISSN:1229-1684 eISSN:2093-8462). All right reserved.

(c)This is an open-access article distributed under the terms of the Creative Commons Attribution Non-Commercial License(http://creativecommons.org/licenses/by-nc/3.0/), which permits unrestricted non-commercial use, distribution, and reproduction in any medium, provided the original work is properly cited. http://www.esk.or.kr 
하는 것이 보통이다. 같은 맥락에서, 인적오류를 "시스템의 효능, 안전성, 성능을 저하시키거나 그럴 가능성이 있는 부적절하거나 바람직하지 않은 인간의 의사결정이나 행동 (Sanders, 1957)"이라고 정의하는 것도 안전인간공학의 일 반적인 경향이다.

이런 측면에서 보자면, 원자력 시설의 기능을 저하시키거 나 정지시킬 수 있는 모든 인간의 행위나 의사결정은 인적오 류라는 범주에 해당한다고 볼 수 있다. 그러므로, 원자력 시 설에 종사하는 수많은 작업자들의 사고를 예방한다는 것은 바꾸어 말하자면 많은 부분이 그들의 인적오류를 예방하는 일로 귀결된다고 할 수 있다. 특히 원자력 발전소의 정상적 인 작업수행은 상당 부분 주제어실에 근무하는 작업자들에 의하여 좌우되므로, 이들의 인적오류를 예방하는 일은 원자 력 발전소의 원활한 작업수행을 위하여 필수적인 일이 아닐 수 없다.

인적오류에는 작업자 자신의 신체적, 정신적, 심리적 요인 은 물론, 작업자가 작업하는 작업환경, 작업관리 조직 및 관 리 방법, 그리고 배후요인으로서의 사회심리학적 요인에 이 르기까지 실로 예상할 수 없을 만큼 다양한 요인이 영향을 미친다는 것은 주지의 사실이다.

더욱이, 미국 TMI \#2 원전의 노심용융 사고에서는 주제어 실과 비상대응설비의 인터페이스(man-machine interface) 및 절차서의 문제, 프랑스 상로랑 원전의 핵연료봉 사고에 서는 부분적 자동화의 문제, 구 소련 체르노빌 원전 화재폭 발 사고에서는 종사자의 의사소통(communication)과 협 력(teamwork) 문제, 일본 $\mathrm{JCO}$ 임계사고 및 동경전력 은 폐/허위보고 사건에서는 관행 등 조직문화(organizational culture) 요소가 인적오류와 관련된 요소로 지적되는 등, 원 자력 안전을 위해 인간공학적으로 대처해야 할 기술적 범위 는 점진적으로 확대되고 있다.

이렇게 다양한 요인들이 복합적으로 작용하여 인적오류를 야기시키는 메커니즘이나, 해당 요인들의 상호관계를 이해하 거나 적어도 설명할 수 있다면, 인적오류를 예방하거나 지연 시키는 중요한 실마리를 얻을 수 있을 것이다. 그런 까닭에 원자력 시설과 관련된 인간공학 분야에서는 작업자의 인적 오류 가능성을 정량적으로 예측할 수 있는 방법에 대하여 많은 연구자들이 적지 않은 노력을 기울여 왔다(Stillwell et al., 1982; Beare et al., 1984; Comer et al., 1984; Dhillon, 1986).

그러나, 그런 노력에도 불구하고 아직 결실은 기대할 만 하지 못하다고 할 수 있다. 왜냐하면 인적오류의 영향을 파악하고자 하는 분석의 대부분이 사건 발생 후 회고적 (retrospective)인 접근 방법을 취하는 사후평가이거나, 사 전분석이라 하더라도 정량적 확률 계산에 국한된 인간신뢰 도분석 (HRA)이거나 포괄적인 안전문화 수준을 정성적으로
평가하는 방법에 그치고 있어서, 근본적으로 인적오류의 가 능성을 평가하는 데에는 한계가 있기 때문이다.

예를 들어, 인간신뢰성에 관한 기존의 연구는 통상 인적오 류확률의 추정에 집중되어 왔다. 그러나, 그런 연구들은 언 제 인적오류가 발생하는지, 또는 특정 상황에서 발생하는 인 적오류를 예방하기 위하여 시스템 설계나 운전 기술을 어떻 게 바꾸면 좋을지 규명하지 못한다. 사고 예방을 위하여 요 구되는 것은 인적오류에 대한 인과관계의 규명이다. 즉, 인 적오류의 원인을 이해하고, 작업자의 수행도를 저하시키는 인과 모델을 구성하여, 어떻게 인적오류의 원인을 회피할 수 있는가를 이해하는 일이다.

지난 몇 십 년 동안 원전 관련 시설의 인간-기계 인터페 이스 관련 인간공학 기술은 급격히 발전한 데 비하여, 시설 의 운영에 요구되는 종사자, 근무, 조직 등에 대한 기술 발전 은 상대적으로 미진한 상태이다. 이를 극복하기 위하여 체르 노빌 사고 이후 국제원자력 안전협약에 의해 근무, 자격, 훈 련, 업무량, 안전문화, 조직행정체계 등 인적요소에 대한 평 가를 원자력법 및 시행규칙에 포함하여(제19조, 45조, 57조 등) 인적오류관리, 주기적안전성평가(PSR: Periodic Safety Review) 등의 요건을 요구하고 있으나, 구체적인 평가 및 관리 기술은 물론 기술 기준도 불확실한 상태이다. 더욱이 근년 원전의 수출과 관련하여 원전 종사자의 건전성 $(\mathrm{FFD}$ Fitness-For-Duty) 기준 등 상세 기술 기준 제시를 위해 서도 기술 개발 및 정립은 매우 시급한 상황이다.

본 연구에서는 원자력 발전소 작업자의 인적오류 가능성 을 증가시킬 수 있는, 다시 말해 작업수행도를 저하시킬 수 있는 직무 스트레스 및 피로, 근무시간 등 인간공학적 위험 요소에 관한 국제 기준 및 지침들을 수집하여 그 내용을 비 교, 분석하고 이후 사고 예방을 위한 관리지침 개발의 연구 방향을 제시하고자 하였다.

\section{Overseas Research Trends}

\subsection{Relationships among stress, strain and fatigue}

이제까지 작업자의 수행도를 저하시키는 요인들의 영향은 대체로 부하(workload) - 스트레스(stress) - 부담(strain) - 피로(fatigue)의 도식(schema)에 기초하여 생각되어 왔 다. 그러나, 부하, 부담, 스트레스, 피로에 대하여 각각의 개 념의 차이와 관계를 명확하게 의식하여 검토한 보고는 극히 적으며, 연구자에 따라 개념에도 차이가 있어 용어 사용상 혼동하기 쉬운 부분이 있으므로, 우선 그 의미를 명확히 이 해할 필요가 있다.

국제표준화기구(International Organization for Stand- 
ardization, ISO)는 1981년 작업 시스템 설계를 위한 인간 공학적 원칙 (Ergonomic principles in the design of work systems)을 제정하고 기본적 용어에 대하여 정의를 시도하 였다. 이후 1985 년과 2004년도 개정에 의하여 다소 변화는 있지만, 그 의미는 대체로 다음과 같다. 즉,

- 작업스트레스(work stress)란 "작업 시스템에 있어서 사 람의 생리적, 심리적 상태를 교란시키도록 작용하는 외적 조건이나 요구의 총량"으로서, 외적 부하(external stress) 라고 부기하고 있다.

- 작업부담(work strain)은 "작업 부하가 개인의 특성이나 능력과 관련하여 미치는 영향"으로서 내적 반응(internal reaction)이라고 부기되어 있다.

- 피로(fatigue)는 "정신적 혹은 신체적인, 또한, 국소 혹은 전신에 대한 과도한 부하에 의해서 나타나는 상태로서, 휴 식하면 완전하게 회복될 수 있는 것"을 말하며, 특히 정신 피로(mental fatigue)는, "정신적 부담의 힘이나 지속 시 간 등의 영향을 받는 정신적, 신체적 기능의 효율의 일시 적인 감퇴로, 휴식 등의 회복작용으로 소실하는 것(ISO 10075-1, 2000)"이라고 정의되어 있다.

이런 개념 설정은 미국 산업안전보건연구원(National Institute of Occupational Safety and Health, NIOSH) 도 마찬가지이어서, $\mathrm{NIOSH}$ 에서는 직업성 스트레스의 Hurrell J.J. Jr 등 $(1988,1998)$ 의 문헌적 내용분석에 기초하여 Figure 1 과 같은 직업성 스트레스 모델을 개발하였다. 작 업에 관련된 자극원 또는 부하원을 의미하는 스트레스 (stressor)가 작업자의 스트레스 반응에 영향을 미치고, 스 트레스 반응은 인적오류를 유발시켜 사고를 야기시키거나, 장기적으로는 직업병으로 진전될 가능성이 있다고 인식하고 있다.

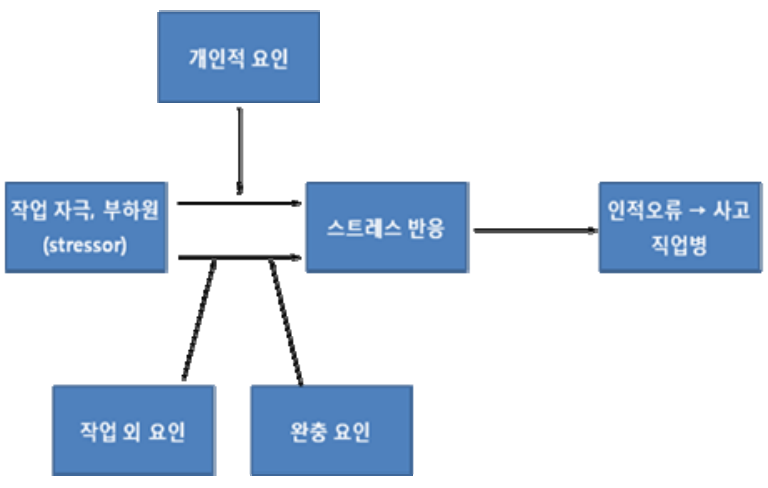

Figure 1. Occupational Stress Model developed by NIOSH

그런데, 여기에서 주의할 것은 스트레스와 피로의 관계이 다. 스트레스와 피로에 대한 연구는 양적인 면에서 상당히
증가한 실정이지만, 연구의 내용을 살펴보면 스트레스와 피 로를 비슷한 개념으로 생각하거나 또는 둘을 서로 종속적인 관계로 보는 연구가 많다. 이에 반하여 피로와 스트레스 각 각에 대한 연구에 비해 피로와 스트레스를 함께 고려한 연 구는 미비하다. Bultmann et al.(2001)의 코호트 연구에 의하면 피로와 스트레스는 유의한 상관관계를 갖고 있지만 이들을 구성하는 기본적인 구성요소도 다르며 개념적, 기능 적, 요인적으로 다르다고 하였다. 또한 근로자들의 피로와 스트레스 발생을 예측하는 데에 직무특성이 가장 영향을 미 치기는 하지만, 위험요인을 예측하는 직무특성의 하부요인에 는 상당한 차이가 있는 것으로 나타나 피로와 스트레스를 예방하는 방법에도 차이가 있다는 점을 강조하기도 하였으 므로, 통념적인 개념을 근거로 모델화하는 것은 정량적이고 객관적인 지표를 개발하는 데 있어서는 오히려 장애로 작용 할 수 있다는 점에 유의하여야 한다.

\subsection{Stress assessment}

스트레스의 영향을 평가하는 방법론에 대해서는 아직도 확립되지 못한 상태이다. 산업의학이나 작업생리학 분야에서 는 체내 호르몬 농도나 타액검사 등의 방법이 유용하다고 소 개하고는 있으나, 작업수행도에 영향을 미쳐서는 안 되는 인 간공학적인 접근 방법의 전제를 충족시키지 못하는 방법이 므로, 본 연구의 전개 방법으로는 적절치 못하다.

$\mathrm{ISO}$ 는 선행 연구 결과에 기초하여 Table 1 과 같은 기 법들이 작업자 작업부담 평가에 적절하다고 제시하고 있어 (ISO 10075-3, 2004), 스트레스의 영향을 평가하는 데 고 려해야 하는 요인들을 간접적으로 이해할 수 있다.

Table 1. Assessment techniques for work strain

\begin{tabular}{|c|c|c|c|c|c|}
\hline \multirow[t]{3}{*}{ Techniques } & \multicolumn{5}{|c|}{ Work Stress $\rightarrow$ Work Strain $\rightarrow$ Influence } \\
\hline & \multirow[t]{2}{*}{ Strain } & \multicolumn{4}{|c|}{ Influence } \\
\hline & & Fatigue & Monotony & $\begin{array}{l}\text { Psychological } \\
\text { Saturation }\end{array}$ & Attention \\
\hline Psychophysiology & $\begin{array}{l}\text { HRV } \\
\text { Blood Pressure } \\
\text { GSR } \\
\text { Catecholamine }\end{array}$ & $\begin{array}{l}\text { Recovery Period of } \\
\text { HR }\end{array}$ & $\begin{array}{l}\text { HRV } \\
\text { EOG } \\
\text { Decrease of HR }\end{array}$ & Increase of $H R$ & $\begin{array}{l}\text { HRV } \\
\text { EOG }\end{array}$ \\
\hline Subjective Measure & Effort & Sense of Fatigue & Drowsiness & $\begin{array}{l}\text { Anger } \\
\text { Boredom }\end{array}$ & Drowsiness \\
\hline $\begin{array}{l}\text { Performance } \\
\text { Appraisal }\end{array}$ & $\begin{array}{l}\text { Response Style } \\
\text { Secondary Task } \\
\text { Performance }\end{array}$ & $\begin{array}{l}\text { Work Perírmance } \\
\text { Primaar Task } \\
\text { Performance } \\
\text { CFF }\end{array}$ & Work Performance & Work Performance & Error Rate \\
\hline Task/Job Analysis & . & $\begin{array}{l}\text { Severity } \\
\text { Work Time } \\
\text { Rest }\end{array}$ & $\begin{array}{l}\text { Repetitiveness } \\
\text { Lack of } \\
\text { Environmental } \\
\text { Change } \\
\text { Work Condition }\end{array}$ & Task Simiarity & $\begin{array}{l}\text { Signal } \\
\text { Discriminability }\end{array}$ \\
\hline
\end{tabular}

특이할 만한 것은, 직무 스트레스 $\rightarrow$ 작업부담 $\rightarrow$ 작업에 미 치는 영향 순으로 평가하는 도식을 취하고 있으며, 특히 작 
업에 미치는 영향을 피로, 단조로움, 심리적 포화, 주의로 나 누어 설명하고 있는 점이다. 즉, 단조로움을 직무 스트레스 로 인한 부정적 결과 나타나는 영향의 하나로 간주하고 있 어, 통상 직무 스트레스의 요인으로 보는 다른 연구자들의 시각과 차이를 보이고 있다.

\subsection{Research trends in other international organizations}

국제노동기구(International Labour Office, ILO)에서는 작업 관련 스트레스 포인트들을 쉽게 이해하고 관리할 수 있 는 체크리스트 형태로 개발하여 보급하고 있다(ILO, 2012). 그러나, 이것은 일반 생산현장에서 당면할 수 있는 위험점들 을 개별적으로 소개하는 데 그치고 있어 현장관리에는 활용 도가 높으나, 직무 스트레스와 피로 등의 관리활동에 체계적 인 틀을 제공하는 데에는 활용할 수 없다.

유럽연합(European Union, EU)은 European Agency for Safety and Health at Work를 중심으로 연구 결과를 보고하고 있다(2000, 2002, 2009). 내용은 주로, 유럽 각국 의 안전보건현황의 통계적 분석을 시도하고, 이에 대한 대응 책을 논의하고 있다. 주목할 만한 점은 사회심리적인 접근 방법에 관심을 갖고 진행되고 있다는 점으로, 예를 들어, 직 무 스트레스와 직업성 심장질환의 발병 기전은 Figure 2에 보는 바와 같이 Cooper \& Marshall(1976)의 모델을 도입 하여 설명하고 있다. 이들의 주장에 따르면, 스트레스란 "인 간과 작업환경 사이의 포괄적인 과정을 이루는 동시에 그 과 정을 반영하는 심리적인 상태"를 말하며, 스트레스의 관리를 위해서는 심리적인 접근 방법이 불가피하다고 역설하고 있 다. 이 모델은 작업 스트레스 및 개인적 또는 조직적 결과물

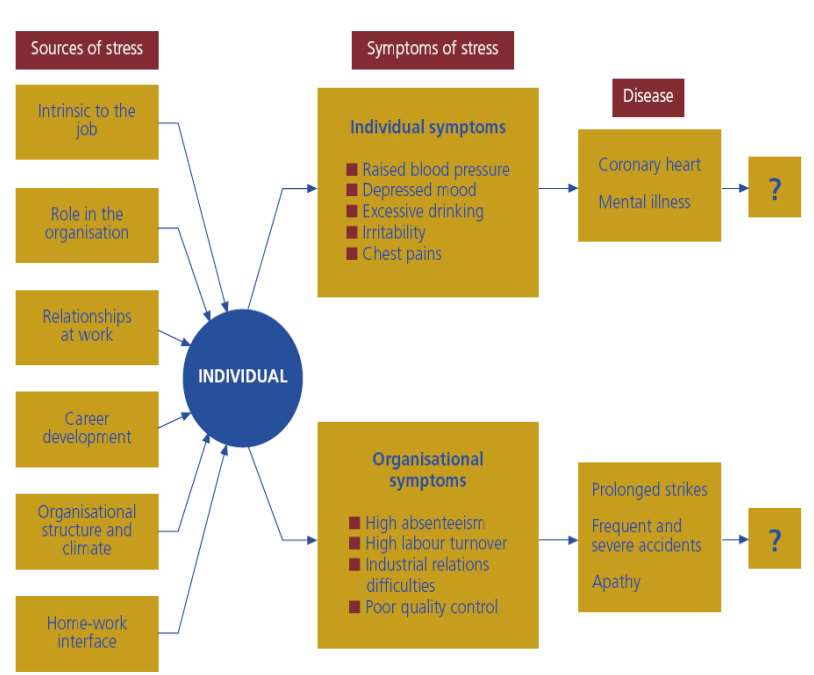

Figure 2. The Dynamics of work stress
의 성질과 상세에 초점을 맞추고 있다. 그 결과, 직무 스트레 스는 자연히 객관적인 작업환경과 개인/조직의 작업환경에 대한 인식간의 문제로 설명되어, 심리적 접근 방법을 강조하 는 데 특징이 있다. 이것은 이후 정신적 스트레스가 정신병 리학적인 질환으로 발전하는 데 대한 설명에 매우 유용하게 활용되는 틀을 제시하고 있다. 관리적 차원에서 유념해야 할 사항으로는, 개인적 스트레스의 차원과 집단적 스트레스의 차원을 별도로 취급하여, 각기 다른 질환으로 발전한다고 설 명하는 점으로, 관리적 해결방안의 차이점을 하나의 모델로 설명해 나가고 있다는 점에서 관리활동의 통일성을 지향하 고 있다.

이 외에 $\mathrm{EU}$ 의 작업 관련 리스크 평가 및 개선방안에 관 한 연구로는 PRIMA-EF를 주목할 수 있는데, 이것은 유럽 각국이 당면하고 있는 노동 관련 사회적 문제를 리스크관리 라는 측면에서 주제를 분류하고 이에 대하여 해결책을 모색 하고 있다. 본 연구 주제와 관련된 사항은 주로 작업 시간의 설정 분야에서 언급되고 있으나, 원자력에 초점을 맞춘 연구 과제는 아니므로 연구 결과를 활용하는 데에는 한계가 있다. Table 2는 PRIMA-EF에서 주로 다루고 있는 연구 주제에 대응하는 EU Directives를 보여준다.

Table 2. Directives related to psychosocial risks

\begin{tabular}{|c|c|}
\hline Psychological issues & Type of document \\
\hline Working time & 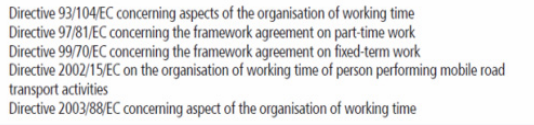 \\
\hline Discrimination & $\begin{array}{l}\text { Directive } 2000 / 43 \mathrm{ECC} \text { and } 2000 / 78 \mathrm{EC} \text { it prohibits direct or indirect discrimination on grounds of } \\
\text { racial or ethnic origin, religion, belief, disability, age, or sexual orientation }\end{array}$ \\
\hline Equal treatment for men and women & 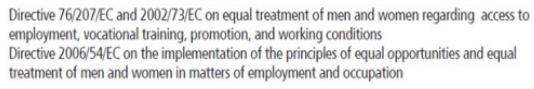 \\
\hline Young people at work & Directive $94333 \mathrm{EC}$ on the protection of young people at work \\
\hline Matemity and related issues & 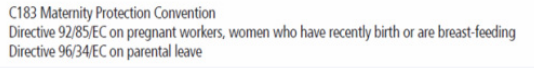 \\
\hline Informing and consulting employees & $\begin{array}{l}\text { Directive 2002/14 EC establishing a general framework for informing and consulting employees } \\
\text { in the European Community }\end{array}$ \\
\hline
\end{tabular}

\subsection{Research trends in national organizations}

국가적 기관으로 주목할 만한 것은 영국 안전보건청 (Health and Safe Executive, HSE)의 노력을 지적할 수 있다. 다른 기관에 비하여 방대한 양의 연구 보고는 물론, 직 접 작업자에게 배포할 수 있는 리플릿이나 브로우셔 형태의 보급물을 다수 개발하고 있다. HSE는 이 밖에도 깊이 있는 연구 보고를 비정기적으로 제출하고 있다. 이 중 2000년대 초에는 직무 스트레스의 심각성과 현황을 보고하는 통계적 분석에 치중한 반면, 2006년 이후부터는 교대작업, 경계 수 
준, 심인성 요인의 영향 등 각론적인 접근을 시도하고 있다.

이에 비하여 미국의 NIOSH에서는 이렇다 할 연구 결과를 제시하지 않고 있다. 개별적인 요인이 미치는 영향에 대해서 는 많은 논문들이 제시되고 있으므로, 이 부분에 대해서는 연구가 더 진행되어야 할 것으로 판단된다.

한편, 미국 항공우주국(National Aeronautics and Space Administration, NASA) 에서는 생리학적인 연구 결과가 다 량 축적되었는데, 괄목할 만한 것으로는 1996년도의 보고서 를 들 수 있다. 이 보고서는 작업자의 작업수행도 저하 및 사고 예방을 위하여 작업-휴식 주기를 어떻게 설정할 것인 가에 대하여 조사하고, 대안을 제시하였다. 2004년도에 발간 된 보고서는 문헌 연구이기는 하지만, 과거의 연구 결과들을 종합하여 직무 스트레스, 스트레스의 인식, 작업수행도의 변 화, 그리고 피로의 관계를 자리매김하는 데 노력하고 있다.

원자력 시설 관련 문건으로는 USNRC 10CFR Part26 Fitness Duty Programs(2008)와 USNRC Regulatory Guide 5.73 Fatigue Management for Nuclear Power Plant Personnel(2009)를 들 수 있으나, 이들은 원자력 시 설 작업자의 직무 스트레스와 피로요인관리의 필요성에 대 해서는 언급하고는 있으나, 지극히 원론적인 원칙만 제시하 고 있어, 현장에서 활용되기에는 많은 거리가 있다.

\subsection{Stress research trend for accident prevention}

사고 예방이나 안전과 관련지어 스트레스를 연구한 연구 문헌은 별로 눈에 띄지 않는다. 극소수가 있기는 하지만, 대 부분 사고와 관련된 직접적인 요인을 평가하는 것이 아니라 사고 발생률과 해당 요인의 점유 비율을 비교함으로써 사고 관련요인들의 영향력을 간접적으로 평가하고자 하는 것이 었다.

예를 들어, 일본 기계시스템진흥협회의 의뢰를 받아 인간 생활공학연구센터가 제출한 보고서에서 인간생활에 대한 다 양한 스트레스를 생리심리학적인 기법을 가지고 평가할 수 있는가, 할 수 있다면 그 결과를 근거로 관리활동을 수행해 나갈 수 있겠는가 하는 질문에 대하여 방법론적인 답을 모색 하고 있다. 그러나, 그 방법론은 업무상의 사고나 상처의 발 생이 비교적 많은 제조업 생산 기능직과 급식 조리원을 대 상으로 직업성 스트레스 조사표를 사용한 자술식 설문 조사 이었다. 그 결과, 남성 제조업 생산 기능직의 경우, 업무상의 사고가 있던 군은 없는 군에 비해 그룹간 대인 갈등, 역할 애매함이 높고, 자존심이 낮고, 직무 만족감이 낮고, 우울성 이 높았다. 반면 여성 제조업 생산 기능직의 경우, 업무상의 사고가 있던 군은 없는 군에 비해, 그룹 내 대인 갈등, 역할 갈등이 높았다고 한다. 그러나, 이런 식의 연구 결과는 사고 와 관련된 인적오류를 유발하는 요인들의 영향을 직접적으
로 평가하거나 정량적인 인과관계를 모델링할 수 없다는 한 계를 안고 있다.

\section{Domestic Research Trends}

\subsection{Research trend}

국내에서의 직무 스트레스와 피로에 관한 연구로는 산업 의학 분야와 작업환경 분야를 중심으로 주로 수행되어 왔다. 그러나, 그 내용이 직무 스트레스의 존재와 직업성 스트레스 질환의 분포에 초점이 맞춰져 있었으며, 더욱이 질환 예방이 라는 측면에서 접근해 왔기 때문에, 사고 예방을 위한 현장 관리 측면에서 활용하기에는 적절치 못하다. 즉, 2005년 피 로에 대한 한국형 평가도구가 개발된 이래, 소방공무원, 제 조업 근로자, 사무직 근로자들에 대한 평가가 이루어지고는 있으나, 이는 만성 질환으로 발전할 수 있는 요인들의 질병 예방적 차원에서 평가하는 것이므로, 인적오류나 사고의 위 험성을 증대시키는 등의 민감한 변화를 파악하고 평가하기 에는 적합하지 못하다.

\subsection{Development of technical guidelines}

직무 스트레스 관리의 필요성은 해당 작업자의 작업수행 도가 저하하여 업무 진행에 차질을 초래한다는 측면에서, 작업의 효율화를 도모하기 위한 산업공학적 측면에서 논의 되어 왔다. 대표적인 예로 한국표준협회(Korea Standard Association, $\mathrm{KSA}$ ) 는 $\mathrm{VDT}$ 작업과 관련하여 작업자의 근골 격계질환을 예방하거나, 시력 및 작업수행도 저하를 예방하 기 위한 관련 지침들이 있을 뿐, 인적오류의 예방에 관한 지 침은 전혀 찾을 수 없다. 더욱이, 대부분의 지침들이 개발 초 기에는 일본의 공업규격(Japan Industrial Standards, JIS) 과의 기술적 대등성, 그리고 최근에는 ISO와의 정합성을 염 두로 개발되어 왔기 때문에 현재 많은 지침들이 폐지되거나 개정 중에 있는데, 이는 ISO와의 저작권 협의가 제대로 이 루어지지 않았기 때문이라고 알려져 있다.

이에 비하여 한국산업안전보건공단(Korea Occupational Safety and Health Agency, KOSHA) 에서는 인적요인으로 인한 사고 및 질병의 예방과 관리를 위하여 총 4 개의 지침 을 개발한 바 있다. 그러나, 그나마 그 중 두 개는 근골격계 질환의 예방을 목표로 하는 것들이어서 작업자의 인적오류 보다는 질환 예방을 목적으로 개발된 것이다. 나머지 두 개 도 인간공학자에 의하여 개발된 것이 아니라, 생산 시스템의 설계라는 틀 안에서 인적요인 관리의 필요성을 부가시키기 위하여 기계설비 분야의 연구진들이 개발한 것이라 용어의 
사용이나 개념적 설정에 있어서 전문성이 미흡하다.

그렇다고 원자력 관련 분야라고 하여 사정이 나은 것도 아 니다. 근년 들어 연이은 기기정지와 잦은 고장으로 인하여 원자력 시설 종사자의 개인적합성 및 조직적 오류에 대비한 건전성 확보의 중요성은 날로 부각되고 있으나, 구체적인 관 리 기준이나 지침이 개발된 바는 아직 없다. 특히, 직무 스 트레스 및 피로, 교대작업주기 등과 같은 개인적합성은 현재 국내의 일부 일반 산업 기준과 USNRC에 의하여 규제 기준 이 제시되고 있으나, 일반 지침에 불과하다. 따라서, 구체적 인 측정 방법은 물론 국내 원자력 분야에 적합한 고유한 기 준 개발이 필요하다. 현재까지 국내에서 시도되어 온 인간공 학 기술은 디지털 원전계측제어계통(KNICS) 개발 과정에 서 주제어실 등 인터페이스(HMI)에 대한 기술이었던 반면, NUREG-0711에서 요구하는 조직 (staffing), 근무, 훈련 (training) 등 종사자와 관련된 인적요소 기술은 상대적으로 미진한 상태이다. 더욱이, 원자력 시설의 종사자 관련 기술 은 해외 선진국에서도 사례가 드물 뿐만 아니라, 한국인 문 화의 고유한 특성이 있어 직접 도입적용이 어렵다고 할 수 있다.

근년 교과부의 위탁을 받아 원자력안전기술원이 수행 한 "가동 중 원전 인적오류 대책 수립에 관한 기초 연구 (2007)"에서는 국내 가동 중 원자력 발전소의 인적오류 방 지를 위하여 수행되어야 할 단기 및 중장기 대책 항목을 도 출하기 위한 정책적 연구이었으며, 한국수력원자력(주)의 위 탁을 받아 한수원중앙연구원이 수행한 "인적오류 저감기술 개발 및 응용(2009 2012)" 과제에서는 원전 가동 중 사고 예방을 위하여 현장에서 시급히 시행되어야 하는 인간공학 규제 현안이 무엇인가를 주 내용으로 하고 있어, 역시 체계 적인 스트레스나 작업수행도 관리에 의한 인적오류 대책과 는 거리가 멀다.

\section{Developing Causality Model for Human Error Possibility Index}

\subsection{General performance shaping factors of NPP workers}

원전 시설의 작업자에게 영향을 미치는 행동형성요인 (Performance Shaping Factors, PSF's) 에는 통상적인 작업 자들이 노출되는 요인들과, 작업 시설이 원전 관련 시설이기 때문에 경험하게 되는 요인이 특별히 부가된다는 것을 상정 할 수 있다. 그런 점에서 Jung et al. (2010)은 기존의 행동 형성요인 분류체계의 장단점을 비교하여 Table 3 과 같은 행 동형성요인 분류체계를 제안하였다. 여기에는 통상적인 행동
형성요인 외에 원자력 시설이라는 특수성 때문에 추가되어 야 하는 요인들이 언급되어 있다.

Table 3. PSF's suggested by Jung et al.(2010)

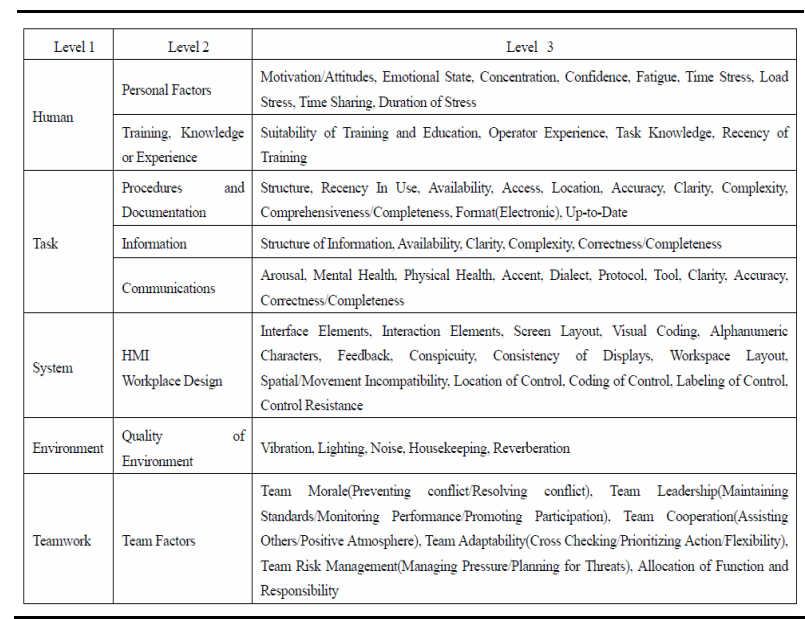

이때, 원전 시설의 특이성이 자칫 간과되기 쉽다. 안전성 이라고 하는 것은 개념적으로 형성되는 개념만이 아니라, 실 무적으로 경험하게 되는 많은 요인들을 포괄한다. 그런 점에 서 측면에서 볼 때, 원전 시설은 다른 산업현장에 비하여 특 이한 성질을 몇 가지 가지고 있다. 예를 들어, 작업자가 위험 점에 직접 접근하지 않아도 위험요인이 작업자에게 위협을 줄 수 있다는 점, 사고가 발생한다면 본인이나 산업현장 주 변의 피해로 끝나는 것이 아니라 국가적인 재앙이 될 수 있 다는 점, 그래서 사고가 발생하면 대피한다는 것을 전제로 하는 안전관리가 아니라, 오히려 위험개소에 접근하여 위험 요인의 확대를 차단하여야 한다는 점 등이다. 따라서, 원전 시설의 작업자가 당면하는 행동형성요인들이 사고와 관련된 인적오류에 어떤 영향을 미치는가 정량적으로 평가하기 위 해서는 다음과 같은 요인들이 추가적으로 심도있게 검토되 어야 한다.

\subsection{Stress effect on team performance}

개인적 차원에서 스트레스는 업무수행 시간과 인적오류 를 증가시키고 정확도를 떨어뜨리는 반면(Jones, 1983; Samman et al., 2002), 정보처리 측면에서도 주의 집중의 폭이 좁게 만드는 변화를 가져온다고 하였다(Wickens et al., 1999).

그러므로, 스트레스는 개인의 의사결정과 업무수행능력을 저하시킬 뿐만 아니라, 팀 차원의 업무수행도에도 영향을 미 친다(Hackman et al., 1975; Karau et al., 1992; Johnston 
et al., 1997; Cannon-Bowers et al., 1998).

팀의 공통적인 업무를 수행함에 있어서 스트레스 하의 팀 구성원은, 동료들과 팀 업무에 대한 주의 집중 범위가 좁아 진다(Driskell et al., 1999). 이 점은 특히 안전 측면에서 매 우 중요한 문제이다. 왜냐하면 이것은 팀의 상황 인식 저하 로 연결되며, 결과적으로 팀의 의사결정과 협동이라는 문제 에 영향을 주기 때문이다.

연구 결과에 따르면 팀 내에서 스트레스 반응은 권한과 의 사결정활동을 상위 계층으로 전가하려는 경향을 보인다고 한 다(Hermann, 1963). 즉, 스트레스 상황에서 낮은 신분이 나 계급의 구성원들은 비상시에 행동을 망설이는 한편 상급 자들을 바라보는 경향을 띠게 된다는 것이다(Driskell and Salas, 1991). 그러나, 현실적으로는 기술 개발이 진행됨에 따라 적지 않은 권한이 조직의 하부 구성원들에게 전가되고 있는 실정이다. 이런 시점에 개인에 대한 스트레스의 영향에 대해서는 많은 연구 결과들이 보고되어 왔지만, 팀의 영향이 나 거동에 대해서는 상대적으로 연구가 소홀하였다(Burke et al., 2005).

\subsection{Team decision making}

팀 의사결정이란 "공통의 목표를 달성하기 위해 상호의존 적인 개인들에 의해서 수행되는 의사결정까지의 도달 과정" 을 말한다(Orasanu and Salas, 1993).

과거 연구들은 팀 의사결정이란 개인적 차원에서 이루어 지는 의사결정의 단순 총합이라고 가정하였다. 그러나, 팀 의사결정은 무엇인가 개인적 의사결정들의 합 이상의 것을 내포하고 있으며, 개인적 의사결정을 간단하게 종합한 것이 라고는 할 수 없다는 주장도 있어 왔다(Orasanu and Salas, 1993; Ilgen et al., 1995). 왜냐하면, 팀 의사결정은 최종 결 정을 얻기 위하여 어떤 형태로든 통합되어야 하는 많은 정보 원 (information sources) 과 업무 관점으로 이루어져야 하기 때문이다. 팀 구성원은 개인적 지식과 정보를 동료 구성원과 공유하여야 한다(Shaw and Penrod, 1964). 그리고, 팀 내 에서 공유되는 정보의 유형과 양은 당면 문제가 구체화되는 방식에 영향을 주게 되며, 이것은 다시 의사결정 과정에서 결과 행동에 영향을 주게 된다. 결과적으로 이런 점 때문에, 개인적 차원에서의 의사결정과 팀 차원에서의 의사결정 양 쪽 모두를 이해하지 않으면 팀 의사결정을 이해할 수 없다. 예를 들어, 개인 수준에서는 각자 일련의 정보 조각과 그 가 중치에 따라 의사결정을 하면 그만이지만, 팀의 구성원은 정 보원과 전문성에서 각각 다른 정보를 얻을 수 있기 때문이며, 설령 같은 정보를 취한다 하더라도 과거의 경험, 전문성, 그 리고 상황적인 측면에서 각기 다른 가중치를 부여할 수 있 기 때문이다(Ilgen et al., 1995).
더욱이, 팀 의사결정 과정은 단계, 단계로 진행되는 의사 결정이 아니라 Figure 3에서 보는 바와 같이 주기적이고 반 복적인 과정으로 이루어진 복잡한 과정이다(Kontogiannis, 1996; Hirokawa et al., 1989a, 1989b). 이러한 특성은 인 간의 자연적 의사결정 과정에서 볼 수 있는데, 정신적 시뮬 레이션을 수행한 후, 인간은 특정 부분을 반복하여 검토하는 과정을 거친다.

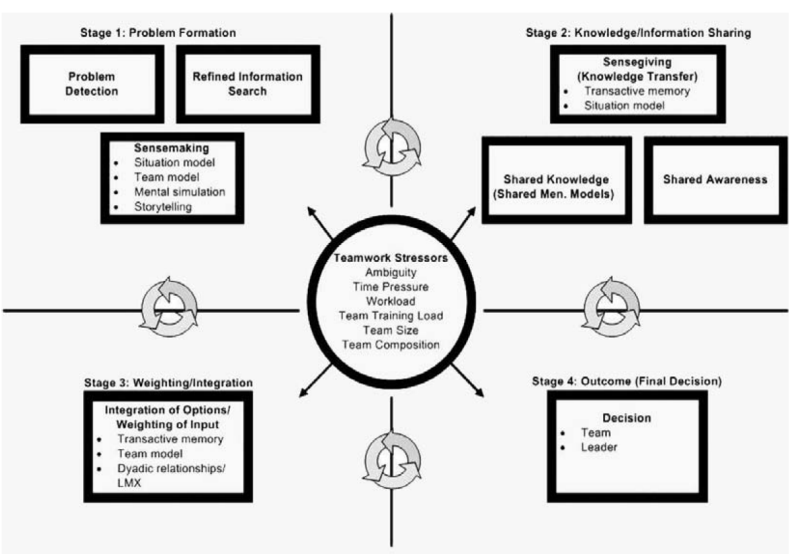

Figure 3. Team decision making under stress framework

비록 팀 의사결정이 복잡한 과정이어서 의사결정 요소와 단서들이 끊임없이 제시되고 재검토되며 정리되어 최종적인 결론에 이른다고는 해도, 그 속도는 팀 구성원들의 인지적 스트레스의 영향을 받게 된다.

더구나, 구성원의 전문성이나 인식된 시간 압박에 따라 발 견적 기법이 이용되기도 하며, 이것은 결국 주기적인 과정을 건너뛰는 결과를 가져오기도 한다(Klein, 1998).

따라서, 팀의 의사결정은 구성원 개개인의 의사결정 과정 을 통하여 예측할 수 없는 역동적인 특성을 갖게 되므로, 원 전 시설 특히 비상시 주제어실에서 대응하는 팀의 반응을 예 측하고자 하는 경우에는 소홀히 다룰 수 없는 복잡한 과제 이다.

\subsection{Efficacy}

자가통제신념(self-efficacy)이나 집단통제신념(collective efficacy)으로 대표되는 이 개념은, 개인이나 팀이 주어진 업무를 수행할 수 있을 만큼 충분한 기술을 가지고 있다는 주관적 인식을 가리키며(Gist, 1987; Bandura, 1997), 스트레스 인식에 중대한 영향을 미친다(Jex et al., 1999; Schaubroeck et al., 2000; Jex and Thomas, 2003). 특히 원전 시설은 비상시 그 피해를 예측할 수 없을 만큼 중대한 
결과를 초래할 수 있으므로, 본인의 행동이 높은 리스크를 가진다는 사실을 인식하게 되면 심리적 스트레스는 더욱 커 져서 평상시와 다른 행동을 할 가능성이 높아진다.

이 때, 자가통제신념이 높은 사람은 좀더 효과적인 문제 해결 접근법을 택하는 반면, 낮은 사람은 문제해결보다는 근심을 포함하는 감정기반 접근법을 택할 가능성이 높다 (Lazarus and Folkman, 1984; Kinicki and Latack, 1990). 한편, 집단통제신념의 경우에도 스트레스 상황에서 팀 내의 지원이나 협조를 증가시킴으로써 스트레스 수준을 저하시 키는 것으로 알려져 있다(Cohen and Wills, 1985; Gore, 1987).

결과적으로, 원전 시설의 비상사태에 대응해야 하는 개인 이나 집단의 통제신념은 본인이나 해당 팀의 신뢰성이나 안 전성에 영향을 미치게 됨은 물론, 해당사태를 안전하게 해결 할 수 있는 가능성에 영향을 미치게 된다.

\subsection{Developing a human error causality model}

인간신뢰성에 관한 연구들은 전통적으로 인적오류율의 통 계적인 추정치 개발에 집중되어 있었다. 그 이유는 작업자인 인간을 원전이라는 시스템의 한 구성요소로 파악하여, 전체 시스템의 신뢰성을 분석하고 파악하는 데 투입되어야 하는 기계의 고장률과 같은 개념으로 이해하였기 때문이다.

그러나, 그런 노력들을 통해서는 언제 인적오류가 발생하 는지 규명하거나, 또 특정 상황에서 인적오류를 예방할 수 있는 시스템 설계나 운영상의 개선점을 제시할 수 없다. 요 구되는 것은 원전의 설계나 운전에 직접적인 영향을 미칠 수 있는 인적오류의 인과관계에 대한 연구라고 할 수 있다 (Moray et al., 1988).

인적오류에 영향을 미치는 요인들의 상호인과관계를 설명

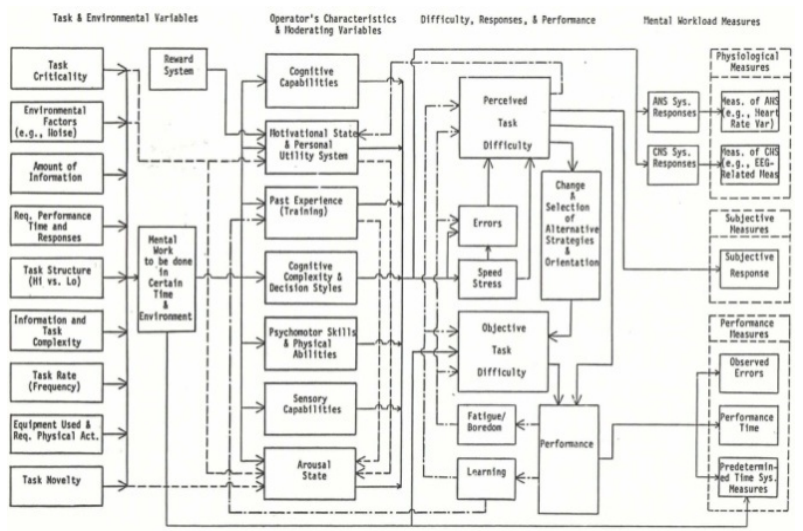

Figure 4. Major components of comprehensive mental workload model and related assessment variables
하고자 하는 노력은 많은 연구자들에 의하여 시도되어 왔다. 앞서 설명한 Figure 1의 NIOSH 모델도 그 중의 하나이고, Figure 2와 같이 Cooper \& Marshall 모델(1976) 도 그 중 의 하나이다. 이런 모델 중에 본 연구의 목적과 관련하여 가 장 주목할만한 것은 Figure 4의 모델이라고 할 수 있다.

이 모델은 Meshkati(1988)에 의하여 개발된 모델로서, 작업자의 정신적 작업부하 요인들의 상호관계를 설명하고 있다. 직접적으로 작업자의 인적오류 발생과 관련된 요인들 의 상호인과관계를 설명하고 있지는 않지만, 많은 요인들의 상호관계를 이해함으로써 정량적인 지표들을 개발함에 있어 서 중요한 실마리를 제공해 줄 것으로 기대된다.

\section{Developing Quantitative Human Error Index}

\subsection{Inventory of job characteristics}

인적오류는 업무수행에 요구되는 능력을 작업자가 감당하 지 못할 때 발생한다는 것이 일반적인 인간공학자들의 견해 이다. 그러므로 우선, 인적오류 발생여부의 기준이 되는 업 무의 요구능력, 즉 업무수행에 요구되는 능력을 어떻게 설명 할 것인가에 관한 연구 결과로는 Fleishman과 그 동료들이 수행한 연구들이 주목할 만하다(Fleishman 1972, 1975a, 1982; Fleishman and Quaintance, 1984).

그들은 많은 연구를 통하여 업무수행에 요구되는 능력들 이 무엇인가를 설명하고자 하였고, 그 결과 능력요건접근법 (Ability Requirements Approach)을 통하여 업무들을 각기 다른 인적오류율을 갖는 집단으로 분류하는 방법론을 개발 하였다(Fleishman 1975b, 1992; Fleishman and Mumford, 1988, 1989, 1991; Fleishman and Quaintance, 1984; Fleishman and Reilly, 1992a, 1992b). 이 접근 방법의 특 징은 다양한 업무들의 업무수행도를 설명할 수 있도록, 가능 한 한 최소한의 독립적인 능력 범주들을 도출하는 것으로서 약 50가지 이상의 능력 범주가 개발되었는데, 각 능력 범주 는 7점 척도를 이용하여 평가하도록 하였다.

이 기법은 연구자료들을 통합하여 비교하는 데 효과적이라 고 알려져 있어서 미국에서 1,100 여 가지의 상이한 업무들 을 비교함으로써 효능이 입증되어, Fleishman Job Analysis Survey (F-JAS)이라는 이름으로 업무비교에 채택되어 활 용되고 있다. 


\subsection{Application of human performance index for accident prevention}

이제까지 몇 가지 인적오류 데이터베이스가 개발되었다고 는 하나, 그 대부분은 주관적 판단에 의존하거나, 인적오류 의 가능성을 예측할 수 있는 자료를 제공하지는 못 하였다. 그러나, 시스템의 안전성을 평가하는 데 있어서 인적요소를 빼놓고 진행한다는 것은 사실상 의미가 반감되기 때문에 인 적오류확률로 대표되는 정량적 지표에 대한 요구는 날이 갈 수록 커져 왔다.

객관적인 인적오류의 빈도자료가 부족하기 때문에 인적오 류 예측기법들의 유효성은 아직 확립되지 못하였으므로, 전 문가들의 판단을 활용하는 방법은 업무수행 중의 인적오류 확률을 예측하는 데 있어서 시간면에서나 비용면에서나 현 실적으로 유용한 방법이다. 그러나, 이 방법은 자료의 신뢰 성에 근본적으로 의문이 있어서 결과의 유용성에 대해서는 근본적으로 한계가 있다.

이에 비하여 시뮬레이터를 이용하는 방법은 비용면에서는 부담이 되지만, 객관적인 자료를 제공한다는 점에서 매력적 이라고 할 수 있다. 여러 학자들은 이런 이유 때문에 시뮬 레이터의 자료를 근거로 인적오류확률 추정을 시도해 왔다. Comer et al.(1984) 등은, Beare et al.(1984)이 제공한

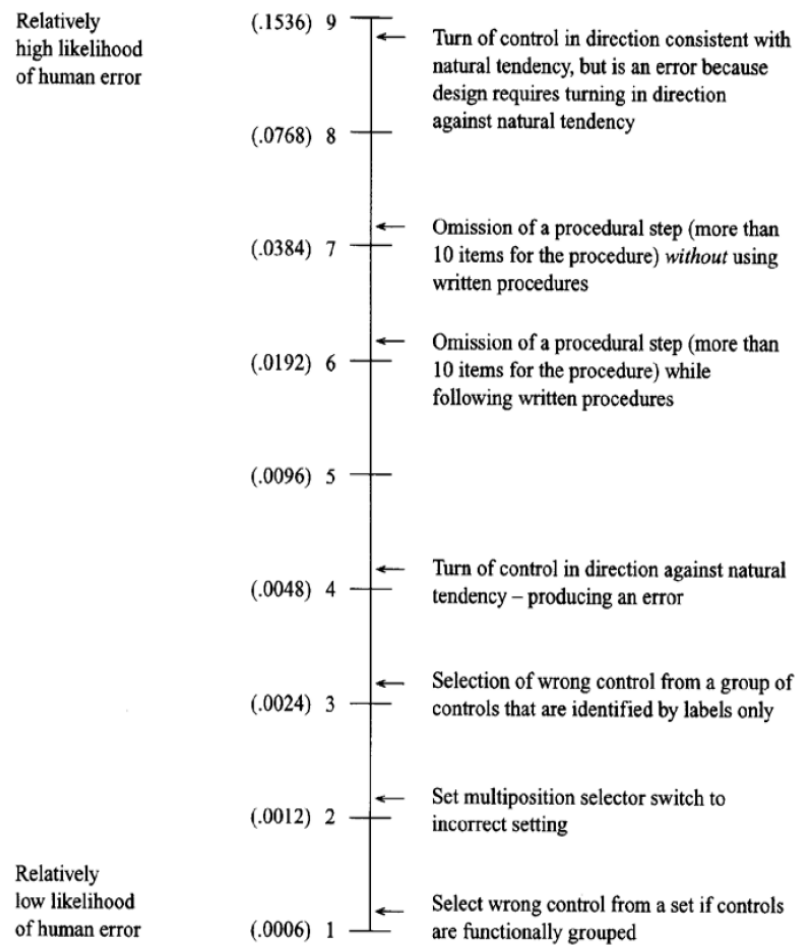

Figure 5. Scale for measuring Human Error Probability(HEP)
원전 시뮬레이터에서의 인적오류 자료들을 이용하여, 인적오 류확률을 직접 추정하는 눈금자를 개발하였다. Figure 5는 그 일부를 보여 준다. 이 눈금자는 $\log _{2}$ 에 기반을 두고 있 는데, 이는 쌍대비교에 근거하는 인간의 판단으로부터 직접 인적오류확률을 추정하는 데 효과적이라고 한다.

이 눈금자를 이용하여 원전의 계장 기술자들 및 운전원들 을 대상으로 수행된 연구 결과에 따르면, 원전의 유형에 따 라 다소 차이가 있기는 하지만, 같은 업무를 수행하는 데에 대해서 전문가들은 상당히 일관성있는 인적오류확률을 제시 하였다고 한다. 원전 형태의 차이에도 불구하고 공통적인 업 무에 대하여 제시된 인적오류확률간에 0.51 내지 0.67 정도 의 높은 상관계수가 존재한다는 것은 인적오류확률을 예측 하는 데 이 기법의 활용 가능성이 있음을 시사한다. 더욱이 제시된 인적오류확률에 대하여 수행된 분산분석 결과에 따 르면 원전 유형, 업무, 그리고 원전 유형 $\times$ 업무의 교호작용 이 통계적으로 유의하다고 판단되어, 그 가능성을 더하였다.

앞서 제시된 Fleishman의 연구 결과와 비교하여 말하자 면 원전의 형태나 업무에 관계없이 작업자의 인지능력은 인 식-운동 능력보다 인적오류확률과의 상관도가 일관성있게 높았고, 요구되는 업무수행능력들을 독립변수로 하는 다중 회귀분석 계수도 0.734 에서 0.848 에 이를 만큼 높았다고 한다. 계층적 회귀분석(hierarchical multiple regression analysis) 결과에 따르면 문서 이해력(written comprehension) 과 연역적 추론(deductive reasoning)이 원전 유 형이나 업무 차이에 관계없이 인적오류확률을 추정하는 데 중요한 변수로서, 인지능력이 인식-운동 능력보다 인적오 류확률과 더 깊은 관계를 가지고 있다고 한다. 여기에서 말 하는 인식-운동 능력이라 함은 근거리 시각(near vision) 및 손의 교치성(manual dexterity)과 크게 관련 있으며, Rasmussen의 두 가지 인적오류 분류 즉 슬립(slip) 및 미 스테이크(mistake) 분류와 밀접한 관계가 있다.

한편, 기술적인 면에서 이렇게 심리적인 잣대를 인적오류 확률잣대로 변형시킬 때에는 객관적인 인적오류확률을 알고 있는 업무들이 일부 눈금자 구성에 포함되어야 오차를 줄일 수 있다고 Stillwell et al. (1982)은 주장하였다.

그러나, 많은 경우 시뮬레이터에서의 실험적 결과는 통상 적인 작업환경에서 얻어진 결과이기 때문에 시간 스트레스 가 주어지는 경우에는 결과가 달라질 수 있으며 Misumi et al., 2005), 같은 이유로 현장감이 떨어진다는 점에서 비상시 의 인적오류확률을 추정하는 데에는 전용될 수 없다는 데 주 의하여야 한다. 


\section{Discussion and Conclusion}

인적오류가 사고 발생의 많은 부분을 차지하고 있다는 것 은 이미 여러 연구들을 통하여 알려진 사실이다. 그러나, 인 적오류의 발생에 영향을 미치는 수많은 요인들을 하나의 프 레임 안으로 끌어 들이고, 그 요인들의 상호관계를 이해함으 로써 하나의 모델을 만들고, 그것을 기반으로 사고를 야기시 킬 수 있는 가능성을 논하자는 의도는 아직 논의할 바가 많 다고 판단된다. 다만, 적어도 현재까지는 각기 다른 견해와 시각을 가진 연구자들의 의견을 종합하고 연구 결과를 정리 하여 인적오류를 야기시키는 상황을 시뮬레이션하려는 연구 가 개별적 요인을 대상으로 진행되어 온 만큼, 이제는 하나 의 모델로 통합하는 검도해 볼 단계로 옮겨가고 있다고 할 수 있다. 특히, 과거에 인적오류를 작업자 개인적 문제로 이 해해 온 데 비하여 2011년도에 발생한 일본 후쿠시마 원전 의 사고나, 2012년 보고된 고리 발전소의 트러블 은폐기도 는 사고와 관련된 인적 요인, 특히 안전문화와 인적오류 전 반에 대한 관심과 비판을 동시에 불러 일으켜 국내외의 관 심이 증대되는 만큼, 인적오류에 대한 연구 개발이나 규제는 날이 갈수록 강화될 것으로 예상된다. 이러한 상황에서 관리 기술의 지원과 뒷받침없이 최근 국산 원자로 기술이 개발되 고 해외로 수출되고 있음은 안전성이라는 측면에서 볼 때 적 지 아니 우려스러운 일이다.

이런 시점에서 인간공학의 역할은 원자력 기술의 발달에 대응하여, 원전을 관리하고 운용하는 인적 요원들의 작업환경, 작업조건들을 합리화, 최적화하여 사고를 예방하는 일일 것 이다. 그 방법론의 하나로 인간의 작업수행도를 정량화하여 제시함으로써 인적오류의 확률 또는 가능성을 가늠하고 원전 시설 시스템 전체의 안전성을 올바로 평가해 보자는 것이다. 이제까지 살펴 본 바와 같이 작업자의 인적오류를 유발할 수 있는 요인에 대해서는 많은 연구가 수행되어 오고 있으며 그 연관성에 대해서도 곳곳에서 거론되고 있으나, 개별적 연 구자들의 관심과 목적에 따른 연구에 불과하여 포괄적인 이 론으로 정립되지 못하고 있다. 그 주요 영향요인의 중심에 직무 스트레스, 피로 등의 요인이 있지만, 이제까지의 연구 성과는 주로 산업의학과 작업환경분야에서 거론되어 직업성 질환으로 발전되는 데 연구 초점이 맞춰져 있어, 이 연구 결 과들을 토대로 인적오류의 가능성을 논하는 평가도구로 활 용할 수는 없다는 점을 확인하였다.

또한, 원전 시설은 앞에서 살펴 본 바와 같이 일반 산업현 장과 구별되는 특이성을 가지고 있다. 일반적인 산업현장의 작업자에 비하여 고도의 전문지식과 기술, 사고 발생시의 심 리적 부담, 팀웍과 커뮤니케이션에 의한 상황판단(situation awareness) 등이 인적오류 발생에 매우 중요한 요인이다.
본 연구에서 한 두 가지 그 특이성에 대하여 언급하였지만, 연구결과가 일천한 요소들도 예상외로 많아 개별적 요소에 대한 연구는 물론, 인적오류에 미치는 종합적인 연구에 이르 기까지 아직도 많은 연구가 기대된다.

더욱이, 안전문화는 해당 기관이나 시설물관계자들의 고유 문화이기 때문에, 선진국의 연구 결과를 국내에 전용한다거 나 이식한다는 것은 시간면에서나 비용면에서나 많은 노력 을 요할 것이며, 사안에 따라서는 사실상 불가능할 것으로 예상된다. 그런 점에서, 기존의 연구 성과들을 원전 시설에 전용하는 것은 적절치 못하며, 다른 인간공학 분야와 비교 할 때 특히 국산 기술의 개발이 불가피한 분야이다.

어떤 산업현장에든 인적오류율에 영향을 미칠 수 있는 요 인은 헤아릴 수 없을 만큼 매우 많다. 원자력 발전소도 마 찬가지이다. 더욱이 원전 유형이나 조직 분위기는 인적오류 확률에 영향을 미칠 수 있는 중요한 요인이다. 그렇지만 다 른 한편으로 좀 더 세밀한 분석을 하면, 인간의 인지능력이 나 인식-운동 능력 또한 인적오류확률에 영향을 미치는 중 요한 요인이라는 것을 쉽게 알 수 있다. 그러나, 이러한 의문 은 이제까지 많은 사람들의 관심을 끌지 못했다. 무엇보다도 정량적 분석에 이용될 수 있는 확률론적 자료가 절대적으로 부족했기 때문이다(Dhillon, 1986). 정량적 접근 방법이 곤 란한 연구 주제에 대해서는 정성적인 접근 방법이 불가피하 다. 그런 점에서 인적오류는 정량적인 접근방법 외에도 정성 적인 접근 방법을 소홀히 해서는 안 되는 연구대상이다.

원자력 시설에는 작업자 관련 개인, 조직, 근무환경 등의 인적오류 위험요인 등이 망라되어 있어, 작업의 스트레스, 스트레스 반응, 완충요인 등의 직업성 스트레스 각종 요인이 작업자의 인적오류에 어떠한 영향을 미치는지, 또 나아가 국내 원자력 시설의 사고 가능성에 어떠한 영향을 미치는지 이들을 관리 감독할 수 있는 포괄적인 모델이 절대적으로 필 요한 시점에 와 있다.

\section{Acknowledgements}

This research was supported by the nuclear energy research and development project (Grant. 2012M2A8A-4004256) funded by the Ministry of Education, Science and Technology.

\section{References}

Arkin, W.M. and Handler, J., Naval accidents 1945-1988, Neptune papers, 
3, Washington, DC, Institute for Policy Studies, 1989.

Bandura, A., Self-efficacy: The Exercise of Control, New York, NY, Freeman and Company, 1997.

Beare, A.N., Dorris, R.E., Bovell, C.R., Crowe, D.S. and Kozinsky, E.J., $A$ simulator-based study of human errors in nuclear power plant control room tasks, Report NUREG-3309, Albuquerque, NM, Sandia National Laboratories, 1984.

Bell, L.G. and O'Reilly, P.D., Operating experience feedback report Progress in scram reduction, Report NUREG-275, 5, Washington, DC, US Nuclear Regulatory Commission, 1989.

Bento, J.P., Collection, analysis and classification of human performance problems at the Swedish nuclear power plants, In International Atomic Energy Agency (Ed), Human error classification and data collection: Report of a technical committee meeting, Vienna, IAEA, 83-94, 1990.

Burke, K.A., Szalma, J.L., Duley, A., Oron-Gilad, T. and Hancock, P.A., "Testing the Efficiency and Effectiveness of Soldier Performance under Increasing Task Demand", Proceedings of the 49 Human Factors and Ergonomics Society Annual Meeting, 49(pp.2119-2123), Orlando, FL, 2005.

Bultmann, U., Kant, I.J., van Amelsvoort, L.G., van den Brandt, P.A. and Kasl, S.V., Differences in fatigue and psychological distress across occupations: results from the Maastricht Cohort Study of Fatigue at Work, Journal of Occupational and Environmental Medicine, 43(11), 976-983, 2001

Cannon-Bowers, J.A. and Salas, E., Making Decisions under Stress: Implications for Individual and Team Training, 1st ed., APA Books, 1998.

Chartered Institute of Personnel and Development, Building the business case for managing stress in the workplace, UK, 2008.

Cohen, S. and Wills, T.A., Stress Social Support, and the Buffering Hypothesis, Psychological Bulletin, 98, 310-357, 1985.

Comer, M.K., Seabver, D.A., Stillwell, W.G. and Gaddy, C.D., Generating human reliability estimates using expert judgment, Report NUREG/ CR-3688, Washington, DC, US Nuclear Regulatory Commission, 1984.

Cooper, C.L. and Marshall, J., Occupational sources of stress: a review of the literature relating to coronary heart disease and mental ill health, Journal of Occupational Psychology, 49, 11-28, 1976.

Dennig, R.L. and O'Reilly, P.D., Operating experience feedback report New plants, Report NUREG-1275, 1, Washington, DC, US Nuclear Regulatory Commission, 1987.

Dhillon, B.S., Human reliability with human factors, 1st ed., New York: Pergamon Press, 1986.

Driskell, J.E. and Salas, E., Overcoming the Effects of Stress on Military Performance: Human Factors, Training and Selection Strategies, In R. Gal, A.D. Mangelsdorff (Eds), Handbook of Military Psychology, Wiley, London, England, 183-193, 1991.

Driskell, J.E., Salas, E. and Johnston, J.H., Does Stress Lead to a Loss of Team Perspective?, Group Dynamics, 3(4), 291-302, 1999.

Energy Institute, Improving Alertness through Effective Fatigue Management, London, Energy Institute, 2006.
European Agency for Safety and Health at Work, OSH in figures : stress at work-facts and figures, Office for Official Publication of the European Communities, 2009.

European Agency for Safety and Health at Work, OSH in figures: stress at work-facts and figures, European Communities, Luxembourg, Office for Official Publication of the European Communities, 2009.

European Agency for Safety and Health at Work, Prevention of Psychosocial Risks and Stress at Work in Practice, Office for Official Publication of the European Communities 2002.

European Agency for Safety and Health at Work, Prevention of Psychosocial Risks and Stress at Work in Practice, Spain, Office for Official Publication of the European Communities, 2002.

European Agency for Safety and Health at Work, Research on Work-related Stress, Office for Official Publication of the European Communities, 2000.

European Agency for Safety and Health at Work, Work-related Stress, Belgium, Office for Official Publication of the European Communities, 2000.

Fleishman, E.A., On the relation between abilities, learning, and human performance, American Psychologist, 27, 1017-1032, 1972.

Fleishman, E.A., Systems for describing human tasks, American Psychologist, 37, 821-834, 1982.

Fleishman, E.A., Toward a taxonomy of human performance, American Psychologist, 30, 1127-1149, 1975b.

Fleishman, E.A., Fleishman Job Analysis Survey (F-JAS), Bethesda, MD: Management Research Institute, 1992.

Fleishman, E.A. and Mumford, M.D, Evaluating classifications of job behavior: A construct validation of the Ability Requirement Scales, Personnel Psychology, 44, 523-575, 1991.

Fleishman, E.A. and Mumford, M.D, Ability requirement rating scales, In S. Gael (Ed), Handbook of job analysis, Wiley, New York, 1988.

Fleishman, E.A. and Mumford, M.D, Individual attributes and training performance, In I.L. Goldstein (Ed), Training and development in organizations, Jossey-Bass, San Francisco, 183-255, 1989.

Fleishman, E.A. and Quaintance, M.K., Taxonomies of human performance: The description of human tasks, Bethesda, MD: Management Research Institute, 1984.

Fleishman, E.A. and Reilly, M.E., Fleishman Job Analysis Survey (FJAS) administrator's guide, Bethesda, MD: Management Research Institute, 1992a.

Fleishman, E.A. and Reilly, M.E., Handbook of human abilities: Definitions, measurements, and job task requirements, Bethesda, MD: Management Research Institute, 1992b.

Fleishman, E.A., Taxonomic issues in human performance research, In W.T. Singleton, P. Spurgeon (Eds), Measurement of human resources, Halsted Press, New York, 1975a.

Gist, M.E., Self-efficacy: Implications for Organizational Behavior and Human Resource Management, Academy of Management Review, 12, 472-485, 1987.

Gore, S., Perspectives on Social Support and Research on Stress Moderating Processes, In J.M. Ivancevich, D.C. Ganster (Eds), Job Stress: from Theory to Suggestion, Haworth Press, New York, 85-101, 1987. 
Hackman, J.R. and Morris, C.G., Group Tasks, Group Interaction Process, and Group Performance Effectiveness: A Review and Proposed Integration in Advances, In L. Berkowitz, (Ed), Experimental Social Psychology, Academic Press, New York, 47-49, 1975.

Haga S., Theory and Measurement of Mental Workload, The Japanese Publishing Service, 2001 (in Japanese).

Haratani T., Nakata A., Otsuka, Y., Miki, K., Fukuda, H. and Izawa, S., Research on Stress Prevention in the Workplace for Reducing Accidents and Injuries, Report JNIOSH-SRR-No.40, Japan, Japanese National Institute of Safety and Health, 2010 (in Japanese).

Health and Safe Executive (HSE), Investigation of the links between psychological ill-health, stress and safety, Report RR488, UK, Health and Safe Executive, 2006.

Health and Safe Executive (HSE), Managing Shiftwork: Health and safety guidance, Report HSG256, UK, Health and Safe Executive, 2006

Health and Safe Executive (HSE), Managing the causes of work-related stress, Report HSG218, UK, Health and Safe Executive, 2007.

Health and Safe Executive (HSE), The Scale of Occupational Stress: A further analysis of the impact of demographic factors and type of job, Report CRR311/2000, UK, Health and Safe Executive, 2000.

Health and Safe Executive (HSE), The scale of Occupational Stress: The Bristol Stress and Health at Work Study, Report CRR265/2000, UK, Health and Safe Executive, 2000.

Heinrich, H.W., Industrial Accident Prevention, McGraw-Hill, 1931.

Hermann, C.F., Some Consequences of Crisis which Limit the Viability of Organizations, Administrative Science Quarterly, 8, 61-62, 1963.

Hirokawa, R.Y. and Johnston, D.D., Toward a General Theory of Group Decision Making: Development of an Integrated Model, Small Group Behavior, 20(4), 500-523, 1989.

Hurrell, J.J. Jr. et al., Measuring job stressors and strains: where we have been, where we are, and where we need to go, Journal of Occupational Health Psychology, 3(4), 368-389, 1998.

Hurrell, J.J. Jr. and McLaney, M.A., Exposure to job stress - a new psychometric instrument, Scandinavian Journal of Work, Environment \& Health, 14(1), 27-28, 1988.

Ilgen, D.R., Major, D.A., Hollenbeck, J.R. and Sego, D.J., Raising an Individual Decisionmaking Model to the Team Level: A New Research Model and Paradigm, In R. Guzzo and E. Salas (Eds), Team decision making in organizations, Jossey-Bass, San Francisco, CA, 113-148, 1995.

International Labour Office (ILO), Stress prevention at work checkpoints Practical improvements for stress prevention in the workplace, Geneva, 2012.

International Organization for Standardization (ISO), Ergonomic principles related to mental workload: Part 1 General terms and definitions, ISO 10075-1:2000, 2000.

International Organization for Standardization (ISO), Ergonomic principles related to mental workload - Part 3: Principles and requirements concerning methods for measuring and assessing mental workload, ISO 10075-3:2004, 2004.

Jex, S.M. and Bliese, P.D., Efficacy Beliefs as a Moderator of the Impact of Work-Related Stressors: A Multilevel Study, Journal of Applied
Psychology, 84, 349-361, 1999.

Jex, S.M. and Thomas, J.L., Relations between Stressors and Group Perceptions: Main and Mediating Effects, Work and Stress, 17, 158 $-169,2003$.

Johnston, J.H., Driskell, J.E. and Salas, E., Vigilant and Hypervigilant Decision Making, Journal of Applied Psychology, 82, 614-622, 1997.

Jones, D.M., Noise, In R. Hockey (Ed), Stress and Fatigue in Human Performance, John Wiley \& Sons, New York, NY, 1983.

Jung, K., Cho, J. and Byun, S., An Empirical study on Evaluation of Performance Shaping Factors and their influence on Human Error, Journal of the Ergonomic Society of Korea, 10, 72-77, 2010.

Karau, S.J. and Kelly, J.R., The Effects of Time Scarcity and Time Abundance on Group Performance Quality and Interaction Process, Journal of Experimental Social Psychology, 28, 542-571, 1992.

Kinicki, A.J. and Latack, J.C., Explication of the Construct of Coping with Involuntary Job Loss, Journal of Vocational Behavior, 36, 339-360, 1990.

Klein, G., Sources of Power: How People Make Decisions, MIT Press, 1998.

Kontogiannis, T., Stress and Operator Decision Making in Coping with Emergencies, International Journal of Human-Computer Studies, 45, 75-104, 1996.

Korea Occupational Safety and Health Agency (KOSHA), Work Environment Improvement for Preventing Musculoskeletal Disorders, Report H-66-2012, Korea Occupational Safety and Health Agency, 2012 (in Korean).

Korea Occupational Safety and Health Agency (KOSHA), Safety Guide for Prenventing Human Errors in Maintenance Works, Report G-16-2011, Korea Occupational Safety and Health Agency, 2011 (in Korean).

Korea Occupational Safety and Health Agency (KOSHA), Medical Treatment Guide for Preventing Musculoskeletal Disorders in Workplaces, Report H-68-2012, Korea Occupational Safety and Health Agency, 2012 (in Korean).

Korea Occupational Safety and Health Agency (KOSHA), Safety Guide for Human Errors and Behaviors, Report G-22-2011, Korea Occupational Safety and Health Agency, 2011 (in Korean).

Lam, P. and Leeds, E., Operating experience feedback report-Service water system failures and degradations, Report NUREG-1275, 3, Washington, DC, US Nuclear Regulatory Commission, 1988.

Lazarus, R.S. and Folkman, S., Stress, Coping, and Adaptation, Springer Publishing, 1984.

Meshkati, N., Toward Development of A Cohesive Model of Workload, In P.A. Hancock, and N. Meshkati (Eds), Human Mental Workload, Elsevier Science Publishers, 1988.

Misumi, J., Wilpert B. and Miller, R., Nuclear Safety: A Human Factors Perspective, 1st ed., CRC Press, 2005.

Moray, N.P. and Huey, B.M., Human Factors Research and Nuclear Safety, National Academy Press, 1988.

National Aeronautics and Space Administration (NASA), Stress, Cognition, and Human Performance: A Literature Review and Conceptual Framework, Report NASA/TM-2004-212824, Washington, DC, National Aeronautics and Space Administration, 2004. 
National Aeronautics and Space Administration (NASA), Principles and Guidelines for Duty and Rest Scheduling for Commercial Aviation, Report NASA/TM-110404, Washington, DC, National Aeronautics and Space Administration, 1996.

O'Reilly, P.D. and Plumlee, G.L., Operating experience feedback reportTechnical specifications, Report NUREG-1275, 4, Washington, DC, US Nuclear Regulatory Commission, 1988.

Orasanu, J. and Salas, E., Team Decision-Making in Complex Environments, In G. Klein, J. Orasanu, R. Calderwood and C.E. Zsambok (Eds), Decision making in Action: Models and Method, Ablex, Norwood, NJ, 327-345, 1993.

Research Group on Occupational Fatigue, Handbook of Occupational Fatigue, Japan Society for Occupational Health, 1988 (in Japanese).

Samman, S.M. and Salas, E., Stress Exposed: The Unfolding Story, Stress News, 14, 7-11, 2002.

Schaubroeck, J., Lam, S.S.K. and Xie, J.L., Collective Efficacy versus Self-Efficacy in Coping Responses to Stressors and Control: A Cross Cultural Study, Journal of Applied Psychology, 85, 512-525, 2000.

Shaw, M.E. and Penrod, W.T., Group Effectiveness as a Function of Amount of 'legitimate' Information, Journal of Social Psychology, 62, 241-246, 1964.

Skof, M., Human characteristics affecting nuclear safety, In the International Atomic Energy Agency (Ed), Human error classification and data collection: Report of a technical committee meeting, IAEA, Vienna, 95-102, 1990.

Stewart, M. and Melchers, R.E., Probabilistic Risk Assessment of Engineering Systems, Springer, 1997.

Stillwell, W.G., Seaver, D.A. and Schwartz, J.P., Expert estimation of human error probabilities in nuclear power plant operations: A review of probability assessment and scaling, Report NUREG/ CR-2255, Washington, DC, US Nuclear Regulatory Commission, 1982.

The Royal Aeronautical Society, Fatigue and Duty Time Limitations - An International Review, 1997.

United States Nuclear Regulatory Commission (USNRC), Fitness Duty Programs, Report 10CFR Part26, US, Nuclear Regulatory Commission, 2008.

United States Nuclear Regulatory Commission (USNRC), Fatigue Management for Nuclear Power Plant Personnel, Regulatory Guide 5.73, US, Nuclear Regulatory Commission, 2009.

Wickens, C., Gordon, S. and Liu, Y., An Introduction to Human Factors Engineering, 1st ed., Longman, 1999.

Wu, T., Hwang, S., Maintenance error reduction strategies in nuclear power plants, using root cause analysis, Applied Ergonomics, 20, 115-121, 1989

Zech, L.W.J.R., Informal Discussion of Current Issues, In E.W. Hagen (Ed), Conference record for 1988 Institute of Electrical and Electronics
Engineers 4th conference on human factors and nuclear power plants, Institute of Electrical and Electronics Engineers, New York, 40-42, 1988.

\section{Author listings}

Hyeon-Kyo Lim: hklim@chungbuk.ac.kr

Highest degree: $\mathrm{PhD}, \mathrm{ABD}$., Department of Industrial Engineering, KAIST

Position title: Professor, Department of Safety Engineering, Chungbuk National University

Areas of interest: Industrial Ergonomics, System \& Product Safety, Human Error Prevention

Hyunjung Kim: hjkim21@chungbuk.ac.kr

Highest degree: BS, Department of Safety Engineering, Chungbuk National University

Position title: MS Candidate, Graduate School of Safety Engineering, Chungbuk National University

Areas of interest: Human Error, System safety, Industrial Safety

Tong Il Jang: tijang@kaeri.re.kr

Highest degree: $\mathrm{PhD}$, Department of Safety Engineering, Chungbuk National University

Position title: Senior Researcher, Division of I\&C and Human Factors, Korea Atomic Energy Research Institute (KAERI)

Areas of interest: Human Error, System safety, Industrial Safety

Yong Hee Lee: yhlee@kaeri.re.kr

Highest degree: Ms, Department of Industrial Engineering, Seoul National University

Position title: Section Head, Division of I\&C and Human Factors, Korea Atomic Energy Research Institute (KAERI)

Areas of interest: Human Error, HMI, Cognitive System Engineering

Date Received : 2013-01-24

Date Revised : 2013-01-29

Date Accepted : 2013-01-31 